\title{
Safety and tolerability of dienogest in endometriosis: pooled analysis from the European clinical study program
}

This article was published in the following Dove Press journal:

International Journal of Women's Health

15 April 2015

Number of times this article has been viewed

\author{
Thomas Strowitzki' \\ Thomas Faustmann ${ }^{2}$ \\ Christoph Gerlinger 3,4 \\ Ulrike Schumacher ${ }^{5,6}$ \\ Christiane Ahlers ${ }^{7}$ \\ Christian Seitz ${ }^{8}$ \\ 'Department of Gynecological \\ Endocrinology and Reproductive \\ Medicine, University of Heidelberg, \\ Heidelberg, Germany; ${ }^{2}$ Bayer Pharma \\ AG, Global Medical Affairs Women's \\ Healthcare, Berlin, Germany; ${ }^{3}$ Bayer \\ Pharma AG, Global Research and \\ Development Statistics, Berlin, \\ Germany; ${ }^{4}$ Department of Gynecology, \\ Obstetrics, and Reproductive \\ Medicine, University Medical \\ School of Saarland, Homburg/Saar, \\ Germany; ${ }^{5}$ Jenapharm GmbH \& Co \\ KG, Medical Affairs Support, Jena, \\ Germany; ${ }^{6}$ Center for Clinical Studies, \\ Universitätsklinikum Jena, Jena, \\ Germany; ${ }^{7}$ Bayer Pharma AG, Global \\ Integrated Analysis and Lifecycle \\ Management Statistics, Wuppertal, \\ Germany; ${ }^{8}$ Bayer Pharma AG, Global \\ Clinical Development Therapeutic \\ Area Primary Care and Women's \\ Healthcare, Berlin, Germany
}

Correspondence: Thomas Strowitzki Department of Gynecological Endocrinology and Reproductive Medicine, University of Heidelberg, Voßstraße 9, 69II5 Heidelberg, Germany Tel +4962 21567910 Fax +4962 21564099 Email thomas_strowitzki@med.uniheidelberg.de
Background: In four randomized, controlled, European trials, dienogest $2 \mathrm{mg}$ once daily demonstrated significant efficacy for lesion reduction and reduction in pain intensity in endometriosis. We describe a pooled analysis of the safety and tolerability data from these trials to confirm and further characterize the safety profile of dienogest in the treatment of endometriosis.

Methods: All 332 women treated with dienogest $2 \mathrm{mg}$ who participated in the four clinical trials were included in the pooled analyses for safety assessments, including adverse events, laboratory tests, vital signs, body weight, and bleeding patterns. Safety variables were analyzed using descriptive statistics.

Results: Pooled analyses of this large patient population confirmed that dienogest $2 \mathrm{mg}$ is well tolerated, with a favorable safety profile extending over a period up to 65 weeks in women with endometriosis. The most common adverse drug reactions were headache, breast discomfort, depressed mood, and acne, each occurring in $<10 \%$ of women. All these adverse events were generally of mild-to-moderate intensity and associated with low discontinuation rates. The bleeding pattern associated with dienogest $2 \mathrm{mg}$ was well tolerated, and only two women $(0.6 \%)$ reported bleeding events as the primary reason for premature discontinuation. Laboratory and vital sign assessments indicated no safety concerns for dienogest. Estradiol levels were maintained within the low-physiological range, in support of previous evidence indicating that dienogest $2 \mathrm{mg}$ demonstrates therapeutic efficacy without inducing estradiol deficiency.

Conclusion: In this pooled analysis of 332 women with endometriosis, dienogest was well tolerated with a favorable safety profile extending over a period of up to 65 weeks. There is a paucity of randomized trial evidence to support the use of many treatments in endometriosis. These pooled analyses from four clinical trials of dienogest $2 \mathrm{mg}$ represent a contribution to evidence-based medicine in endometriosis, providing outcomes of potential relevance to daily practice.

Keywords: progestins, endometriotic lesions, clinical trials, side effects, women

\section{Background}

Endometriosis is a long-term, recurrent, debilitating disease experienced by approximately $5 \%-10 \%$ of women. ${ }^{1}$ While the cause of endometriosis remains unknown, the growth of functional endometrial tissue outside the uterus represents its defining feature. Pain of differing types, including dysmenorrhea, dyspareunia, and low back pain, is the most common symptom of endometriosis and is the major reason why women seek medical assistance.

There is currently no cure for endometriosis. Surgery is a common treatment choice, but recurrence rates are high: approximately $40 \%-50 \%$ after 5 years. ${ }^{2,3}$ 
Approved medical treatments for relief of the symptoms of endometriosis include gonadotropin-releasing hormone (GnRH) analogs and the androgen, danazol. Both these classes of treatment, however, are associated with suboptimal safety and tolerability that limit their long-term use. ${ }^{4,5}$ A number of progestins offer long-term efficacy but, depending on their pharmacologic profile, can cause weight gain or androgenic effects at the high doses required for efficacy. ${ }^{6}$

Dienogest is an oral progestin that is approved for the treatment of endometriosis at a daily dose of $2 \mathrm{mg}$ in areas including Europe, Japan, Canada, South Africa, Australia, and several countries in Asia, Latin America, and Africa. Dienogest offers unique pharmacologic benefits relevant to the treatment of endometriosis, including potent progestogenic effects that lead to effective endometrial lesion reduction, combined with only moderate suppression of estrogen levels and no significant androgenic, mineralocorticoid, or glucocorticoid activity. ${ }^{7-9}$

Evidence of the efficacy and safety of dienogest in the treatment of endometriosis includes four key regulatory Phase II and Phase III trials performed in Europe that investigated more than 500 women with endometriosis. These four trials comprised a 24-week dose-ranging study; a 24-week active comparator-controlled trial versus the GnRH analog, leuprolide acetate (LA; $3.75 \mathrm{mg}$ ); a 12-week placebo-controlled study; and a long-term, open-label extension study of women in the placebo-controlled study that investigated dienogest treatment for up to 65 weeks. ${ }^{10-13}$ Other trials of dienogest treatment for endometriosis in Europe and Japan have involved additional cohorts of more than 500 women and included efficacy, safety, and longer term studies. ${ }^{14-16}$ Together, these study data for dienogest represent a unique contribution to evidence-based medicine in the field of endometriosis.

In the four key European trials, dienogest at a dose of $2 \mathrm{mg}$ once daily demonstrated significant efficacy for lesion reduction assessed at laparoscopy and a reduction in pain intensity that was significantly superior to placebo and equivalent to a GnRH analog. Pain intensity, measured on a visual analog scale, decreased progressively from baseline and continued to decrease during long-term therapy over more than 1 year.

Dienogest $2 \mathrm{mg}$ once daily was reported in these trials to be generally safe and well tolerated for the treatment of endometriosis. Convincing safety and tolerability data, in combination with proven efficacy, represent key characteristics when choosing an optimal therapy for long-term use in endometriosis. This paper describes a pooled analysis of safety data from the four European trials that tested dienogest in the approved formulation, with the aim to confirm and further characterize the safety profile of dienogest in the treatment of endometriosis.

\section{Methods}

This pooled analysis derives from four trials in the dienogest European study program. ${ }^{10-13}$ These well-designed studies used similar methodologies for data collection and analysis, and together included large numbers of women who are representative of the wider population of endometriosis patients. Details on the study methodologies, including ethical approvals, are described in the individual publications. All trials had full approval from ethics committees according to the German Medicines Act (AMG).

\section{Participants}

Of 514 women with confirmed endometriosis who were included in the four studies, 332 were treated with dienogest $2 \mathrm{mg}$ once daily for study periods between 12 weeks and 65 weeks. ${ }^{10-13}$ The remaining patients were treated with placebo or LA. In all four studies, the safety analyses included women who took study medication at least once and for whom at least one post-baseline observation was available (ie, the "full analysis set"). The criteria for the assessment of safety and tolerability in these trials are described in the following paragraphs on adverse events and laboratory tests.

\section{Adverse events and adverse drug reactions}

Adverse events (AEs) were defined as any unfavorable and unintended sign, symptom, or disease occurring with the use of study medication. AEs were described using the Medical Dictionary for Regulatory Activities or else were converted in the present study to Medical Dictionary for Regulatory Activities terms to permit data pooling. The intensity of AEs was categorized as mild, moderate, or severe. Serious AEs (SAEs) were defined and documented according to international standards.

AEs that were considered by investigators to be at least potentially related to study medication were described as adverse drug reactions (ADRs). Premature discontinuation rates due to AEs were also included for analysis, as an index of overall tolerability.

\section{Laboratory tests}

Safety laboratory tests included hematology, blood chemistry, liver enzyme, glucose metabolism (glycated hemoglobin), lipid, and hormone assessments, which were determined (at minimum) at the baseline visit and the end of treatment in all studies. 


\section{Vital signs}

Systolic and diastolic blood pressure and heart rate were measured at baseline and at every scheduled visit in all studies, with the exception of the dose-ranging trial, which measured blood pressure alone.

\section{Body weight}

Body weight was measured (at minimum) at baseline visit and at the end of treatment in all studies.

\section{Gynecologic examination}

Gynecologic examinations were performed (at minimum) at baseline visit and at the end of treatment in all studies.

\section{Cervical smear}

Cervical smears were performed at screening/baseline visit and at the end of treatment in all studies, with the exception of the dose-ranging trial. Results of the cytological smears were classified at each study site according to the local classification scheme.

\section{Breast examination}

The breasts were examined (at minimum) by palpation at screening and at the end of treatment in all studies. Abnormal findings were recorded as AEs.

\section{Bone metabolism and bone mineral density}

Laboratory measures of bone mineral metabolism and lumbar spine bone mineral density (BMD) were assessed at baseline and at the end of treatment in a patient subgroup from the active comparator-controlled trial, as previously reported. ${ }^{12}$

\section{Bleeding pattern}

Women recorded bleeding events daily on a diary card in the active comparator-controlled, placebo-controlled, and longterm extension studies to provide information on the mean number of days, number of episodes, and duration of episodes with bleeding/spotting or spotting only. ${ }^{10-13}$ Bleeding data were analyzed in 90-day reference periods, as recommended by the World Health Organization. ${ }^{17}$

\section{Statistical approach}

Following the intent-to-treat principle, all women who took study medication at least once were included in the current pooled analyses (full analysis set). All safety variables were analyzed using descriptive statistics (ie, mean, standard deviation, minimum, first quartile, median, third quartile, and maximum) for continuous variables and by absolute and relative frequencies for discrete variables. Boxplots were drawn using first and third quartiles as the bottom and top of the boxes, respectively; medians were indicated by horizontal lines. Whiskers represent the outmost value within the 1.5-fold interquartile range outside the boxes. Extreme values are presented as dots. All statistical analyses were performed using SAS Version 9.2 software (SAS Institute, Inc., Cary, NC, USA).

\section{Results}

\section{Participants}

Demographic characteristics of the participants who received dienogest $2 \mathrm{mg}$ in the four studies and in the pooled group are shown in Table 1. The full analysis set for the pooled assessments included 332 women who were treated with dienogest $2 \mathrm{mg}$ once daily for a mean duration of 39.8 weeks.

Table I Demographic characteristics of women in individual studies and in the pooled dienogest $2 \mathrm{mg}$ group

\begin{tabular}{|c|c|c|c|c|c|c|c|}
\hline \multirow{3}{*}{$\begin{array}{l}\text { Study } \\
\text { description } \\
\text { Treatment duration, } \\
\text { weeks }\end{array}$} & \multirow{3}{*}{$\begin{array}{l}\begin{array}{l}\text { Dose range } \\
\left(^{a}\right.\end{array} \\
24 \\
\text { Dienoge II) }\end{array}$} & \multicolumn{2}{|c|}{$\begin{array}{l}\text { Placebo-controlled } \\
\text { (Phase III) }^{\prime \prime}\end{array}$} & \multicolumn{2}{|c|}{$\begin{array}{l}\text { Comparator-controlled } \\
\text { (Phase III) }^{12}\end{array}$} & \multirow{2}{*}{$\begin{array}{l}\text { Long-term } \\
\text { extension of } \\
\text { placebo study } \\
\text { (Phase III) }^{13} \\
52\end{array}$} & $\begin{array}{l}\text { Pooled } \\
\text { dienogest } \\
2 \text { mg group }\end{array}$ \\
\hline & & \multicolumn{2}{|l|}{12} & \multicolumn{2}{|l|}{24} & & - \\
\hline & & Dienogest & Placebo & Dienogest & Leuprolide & Dienogest & Dienogest \\
\hline & $2 \mathrm{mg}$ & \multicolumn{2}{|l|}{$2 \mathrm{mg}$} & $2 \mathrm{mg}$ & acetate & $2 \mathrm{mg}$ & $2 \mathrm{mg}^{\mathrm{b}}$ \\
\hline No of patients & 29 & 102 & 96 & 120 & 128 & 168 & 332 \\
\hline Age, years, mean $\pm S D$ & $27.6 \pm 7.3$ & $31.5 \pm 6.7$ & $31.4 \pm 6.0$ & $30.6 \pm 6.2$ & $31.0 \pm 5.8$ & $31.9 \pm 6.4$ & $30.9 \pm 6.5$ \\
\hline (range) & $(16-43)$ & $(18-44)$ & $(19-46)$ & $(18-47)$ & $(18-45)$ & $(18-46)$ & $(16-47)$ \\
\hline Height, $\mathrm{cm}$, mean \pm SD & $168.4 \pm 6.9$ & $165.5 \pm 5.2$ & $166.7 \pm 5.3$ & $166.1 \pm 7.3$ & $166.3 \pm 6.6$ & $166.4 \pm 5.08$ & $166.4 \pm 6.2$ \\
\hline Weight, $\mathrm{kg}$, mean \pm SD & $63.0 \pm 8.9$ & $62.4 \pm 10.3$ & $62.6 \pm 10.8$ & $62.5 \pm 10.8$ & $62.7 \pm 9.6$ & $63.3 \pm 10.7$ & $62.9 \pm 10.4$ \\
\hline $\mathrm{BMI}, \mathrm{kg} / \mathrm{m}^{2}$, mean $\pm \mathrm{SD}$ & $22.3 \pm 3.2$ & $22.7 \pm 3.5$ & $22.5 \pm 3.5$ & $22.6 \pm 3.4$ & $22.7 \pm 3.2$ & $22.8 \pm 3.5$ & $22.7 \pm 3.4$ \\
\hline
\end{tabular}

Notes: ${ }^{\mathrm{D} D a t a}$ for $1 \mathrm{mg}$ and $4 \mathrm{mg}$ groups not shown. ${ }^{b}$ Number of pooled patients is not equal to the sum of patients in the individual dienogest $2 \mathrm{mg}$ groups because patients in the long-term extension study ${ }^{13}$ were enrolled from the placebo-controlled study ${ }^{12}$ and 87 of these 168 patients had already received dienogest in the placebocontrolled study.

Abbreviations: BMI, body mass index; SD, standard deviation. 
The participants were generally similar with regard to demographics and history across the four trials. More than 95\% of women were Caucasian.

The proportions of women who completed or prematurely discontinued study medication are shown in Table 2. Overall, $89.2 \%$ of women treated with dienogest $2 \mathrm{mg}$ completed the planned study durations, including $90.5 \%$ who completed the long-term extension study. Lack of efficacy was reported by only one woman $(0.3 \%)$ in the pooled population as the reason for premature discontinuation.

\section{AEs and ADRs}

Consistent with the four individual studies, the most common ADRs in the pooled population treated with dienogest $2 \mathrm{mg}$ were headache, breast discomfort, depressed mood, and acne (Table 3). Each ADR was reported in $<10 \%$ of women, with headache being the most common $(9.0 \%)$. By contrast, headache was reported in $21.1 \%$ of LA-treated women in the active comparator study, while "hypoestrogenic" ADRs were also common in the LA group, including vulvovaginal dryness (7.0\%), loss of libido (6.3\%), and hot flushes $(6.3 \%){ }^{12}$ Incidences of "hypoestrogenic" ADRs in the pooled population treated with dienogest $2 \mathrm{mg}$ were: vulvovaginal dryness $(0.6 \%)$, loss of libido (1.5\%), and hot flushes $(2.7 \%)$.

Breast discomfort was reported in 18 (5.4\%) women treated with dienogest $2 \mathrm{mg}$, including the reported terms: breast tenderness $(n=11)$, breast engorgement $(n=4)$, and breast pain $(n=3)$.

The bleeding pattern associated with dienogest $2 \mathrm{mg}$ was generally well tolerated, and only two women $(0.6 \%)$ reported bleeding events as the primary reason for premature discontinuation (diary data on bleeding patterns are described).

AEs in the pooled population treated with dienogest $2 \mathrm{mg}$ were generally mild or moderate in intensity and were associated with low premature discontinuation rates. In total, $18 \mathrm{AEs}$ in $15(4.5 \%)$ women led to study discontinuation (Table 2). The study discontinuation rates associated with dienogest $2 \mathrm{mg}$ were broadly consistent across studies, including the long-term extension study and were similar to those reported for LA in the 24-week active comparator-controlled study (ie, 12 events in 5 [3.9\%] women). ${ }^{11,12}$ No individual AE was responsible for increased premature discontinuation in more than $1 \%$ (ie, in more than three women) in the dienogest $2 \mathrm{mg}$ group.

In total, 12 SAEs were reported in 11 women in the pooled dienogest $2 \mathrm{mg}$ group. Three women had SAEs that the investigators rated as "probably related" or "possibly related" to the study medication (two cases of depression and one case of ovarian cyst). Following a conservative approach, one additional event of ovarian cyst that had been assessed as "not related" to the study medication by the investigator was retrospectively rated as "probably related" by the medical experts of the study sponsor. Based on the characteristics of the events and the conditions of their occurrence, the remaining SAEs (ie, breast cancer, cholelithiasis, chronic sinusitis, hospitalized because of pelvic pain, hospitalized because of abdominal pain, kidney calculus/renal colic [two events in one patient], and planned hysterectomy) were considered unlikely to be related to the study medication by the respective investigators.

Table 2 Proportions of women completing planned study duration and reasons for premature discontinuation: individual studies and the pooled dienogest $2 \mathrm{mg}$ group

\begin{tabular}{|c|c|c|c|c|c|c|c|}
\hline \multirow{3}{*}{$\begin{array}{l}\text { Study description } \\
\text { Treatment duration, } \\
\text { weeks }\end{array}$} & \multirow{2}{*}{$\begin{array}{l}\begin{array}{l}\text { Dose range } \\
\text { (Phase II) }^{10}\end{array} \\
24\end{array}$} & \multicolumn{2}{|c|}{$\begin{array}{l}\text { Placebo-controlled } \\
\text { (Phase III) })^{I I}\end{array}$} & \multicolumn{2}{|c|}{$\begin{array}{l}\text { Comparator- } \\
\text { controlled (Phase III) }\end{array}$} & \multirow{2}{*}{$\begin{array}{l}\text { Long-term } \\
\text { extension } \\
\text { (Phase III) }^{13} \\
52\end{array}$} & \multirow{2}{*}{$\begin{array}{l}\text { Pooled } \\
\text { dienogest } \\
2 \text { mg group } \\
-\end{array}$} \\
\hline & & 12 & & 24 & & & \\
\hline & Dienogest & Dienogest & Placebo & Dienogest & Leuprolide & Dienogest & Dienogest \\
\hline & $2 \mathrm{mg}$ & $2 \mathrm{mg}$ & & $2 \mathrm{mg}$ & acetate & $2 \mathrm{mg}$ & $2 \mathrm{mg}^{\mathrm{b}}$ \\
\hline Total & $29(100.0 \%)$ & $102(100.0 \%)$ & $96(100.0 \%)$ & $120(100.0 \%)$ & $128(100.0 \%)$ & $168(100.0 \%)$ & $332(100.0 \%)$ \\
\hline Completed & $24(82.8 \%)$ & $98(96.1 \%)$ & $90(93.8 \%)$ & $109(90.8 \%)$ & $120(93.8 \%)$ & $152(90.5 \%)$ & $296(89.2 \%)$ \\
\hline Discontinued & $5(17.2 \%)$ & $4(3.9 \%)$ & $5(5.2 \%)$ & $\mathrm{II}(9.2 \%)$ & $8(6.3 \%)$ & $16(9.5 \%)$ & $36(10.8 \%)$ \\
\hline ND/UNK/NA & $0(0.0 \%)$ & $0(0.0 \%)$ & I (I.0\%) & $0(0.0 \%)$ & $0(0.0 \%)$ & $0(0.0 \%)$ & $0(0.0 \%)$ \\
\hline \multicolumn{8}{|c|}{ Reason for premature discontinuation } \\
\hline Adverse event & $3(10.3 \%)$ & $2(2.0 \%)$ & I (I.0\%) & $6(5.0 \%)$ & $5(3.9 \%)$ & $4(2.4 \%)$ & 15 (4.5\%) \\
\hline Lack of efficacy & $0(0.0 \%)$ & $0(0.0 \%)$ & $0(0.0 \%)$ & $0(0.0 \%)$ & $0(0.0 \%)$ & I $(0.6 \%)$ & I (0.3\%) \\
\hline Otherc & $2(6.9 \%)$ & $2(2.0 \%)$ & $4(4.1 \%)$ & $5(4.1 \%)$ & $3(2.4 \%)$ & II (6.6\%) & $20(6.0 \%)$ \\
\hline
\end{tabular}

Notes: a Data for I mg and $4 \mathrm{mg}$ groups not shown. ${ }^{b}$ Number of pooled patients is not equal to the sum of patients in the individual dienogest 2 mg groups because patients in the long-term extension study ${ }^{13}$ were enrolled from the placebo-controlled study ${ }^{12}$ and 87 of these 168 patients had already received dienogest in the placebo-controlled study. 'Other reasons for discontinuation included protocol deviation, withdrawal of consent, patient lost to follow-up, and reason unknown.

Abbreviation: ND/UNK/NA, not done/unknown/not assessable. 
Table 3 Most frequently reported adverse drug reactions ( $\geq 3 \%)$ in the pooled dienogest $2 \mathrm{mg}$ group

\begin{tabular}{ll}
\hline ADR (MedDRA preferred term) & No (\%) patients \\
\hline Total population & $332(100.0 \%)$ \\
Headache & $30(9.0 \%)$ \\
Breast discomfort & $18(5.4 \%)$ \\
Depressed mood & $17(5.1 \%)$ \\
Acne & $17(5.1 \%)$ \\
Nausea & $14(4.2 \%)$ \\
Weight increased & $12(3.6 \%)$ \\
Abdominal pain & $12(3.6 \%)$ \\
Asthenic conditions & $10(3.0 \%)$ \\
Flatulence & $10(3.0 \%)$ \\
Ovarian cyst & $10(3.0 \%)$ \\
\hline
\end{tabular}

Note: Mean treatment duration: 39.8 weeks.

Abbreviations: ADR, adverse drug reaction; MedDRA, Medical Dictionary for Regulatory Activities.

\section{Laboratory tests}

Hematology, blood chemistry, and liver enzyme parameters remained generally stable in the pooled dienogest $2 \mathrm{mg}$ group, as well as the comparator groups. Mean concentrations of blood lipids (ie, total cholesterol, triglycerides, low-density lipoprotein cholesterol, and high-density lipoprotein cholesterol) in the pooled dienogest $2 \mathrm{mg}$ group were similar to lipid concentrations in placebo-treated women, ${ }^{11}$ and they remained stable over a treatment period of up to 65 weeks $^{13}$ (Table 4).

Mean glycated hemoglobin levels were stable over time in the pooled dienogest $2 \mathrm{mg}$ group (Table 4 ) and were similar to the normal-range glycated hemoglobin levels reported for LA and placebo in the individual studies. ${ }^{11,12}$

Mean estradiol levels in the pooled dienogest $2 \mathrm{mg}$ group did not change substantially during the treatment period of up to 65 weeks (Table 4). Women treated with dienogest $2 \mathrm{mg}$ showed similar mean estradiol levels at 12 weeks compared to women treated with placebo, whereas LA-treated women showed a marked decrease in mean estradiol concentrations from $299.0 \mathrm{pmol} / \mathrm{L}(81.5 \mathrm{pg} / \mathrm{mL})$ at baseline to $68.5 \mathrm{pmol} / \mathrm{L}$ $(18.7 \mathrm{pg} / \mathrm{mL})$ after 24 weeks. ${ }^{11,12}$

\section{Vital signs}

Mean heart rate and blood pressure were relatively stable over time in the pooled dienogest $2 \mathrm{mg}$ group (Table 4), as they were in the comparator groups. Individual occurrences of abnormal vital signs were rare in all studies.

\section{Body weight}

The body weight analyses included women who provided both baseline and end-of-treatment data. Body weight increased slightly over time in all treatment groups (including

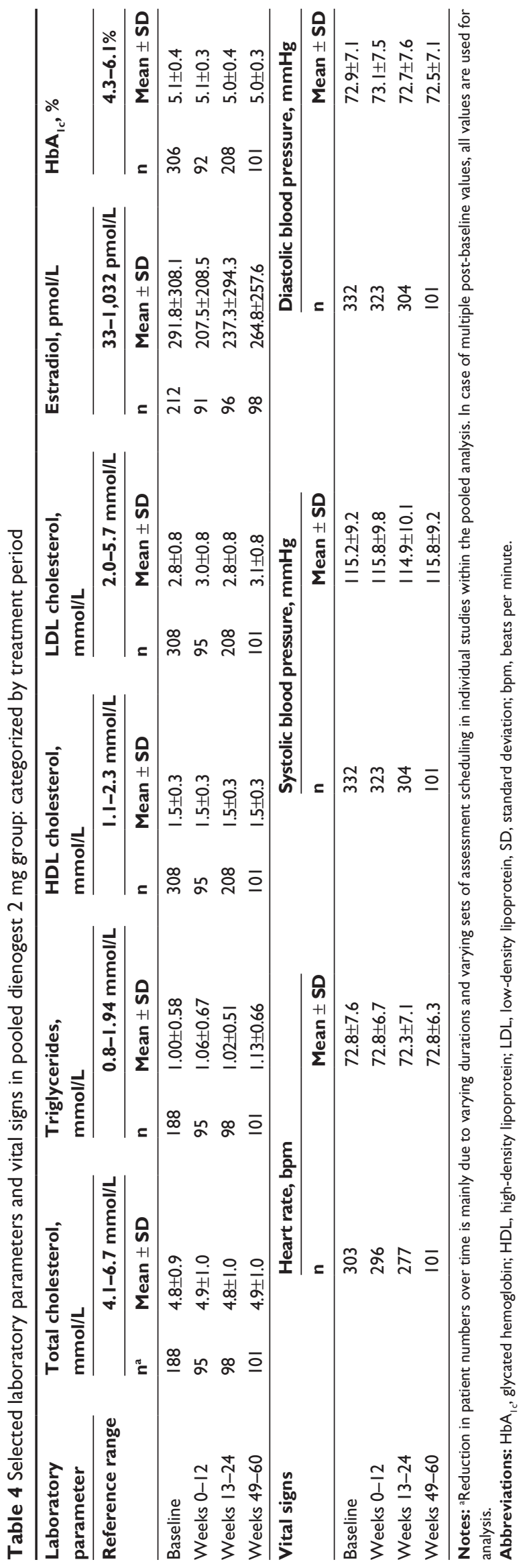




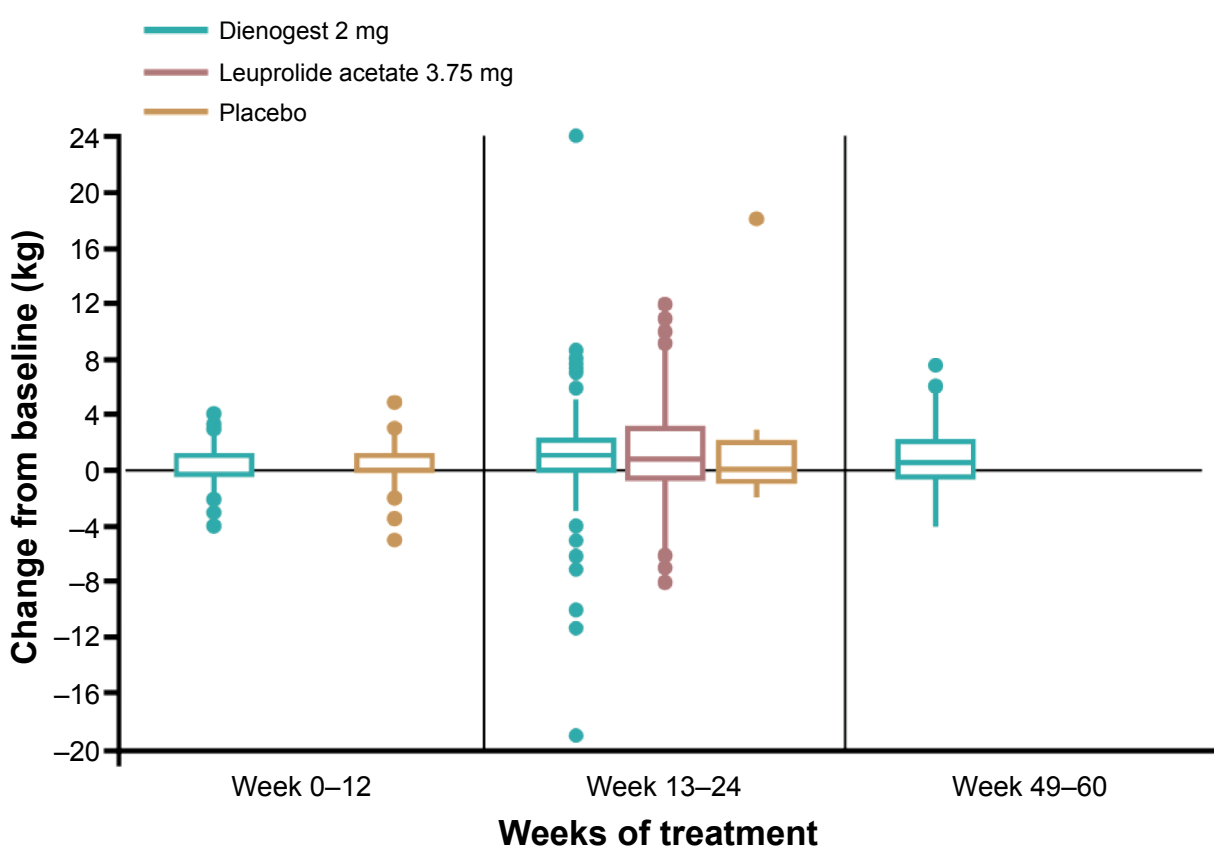

Figure I Change in body weight in pooled dienogest $2 \mathrm{mg}$ group, versus placebo " and leuprolide acetate ${ }^{12}$ groups. Note the differences in treatment duration between the groups.

the placebo group) during treatment for up to 24 weeks. No further increase was observed in the patient group treated with dienogest $2 \mathrm{mg}$ for longer than 24 weeks (Figure 1).

\section{Gynecologic examination}

Gynecological examinations were performed at baseline and during treatment in all studies. However, due to different documentation of findings in the individual studies, meaningful pooling of data was not possible.

\section{Cervical smear}

Of 276 women treated with dienogest $2 \mathrm{mg}$ who had normal results for smear assessment at baseline, three women (1.1\%) had an abnormal smear result at the end of treatment, which in each case was considered unlikely to be related to treatment.

\section{Bone metabolism and BMD}

As previously reported, dienogest $2 \mathrm{mg}$ was associated with minimal changes in bone turnover markers (bone alkaline phosphatase, osteocalcin, and urinary CrossLaps) and in lumbar spine BMD at 24 weeks. ${ }^{12}$ LA-treated women showed increases in bone turnover markers and a clinically relevant reduction in lumbar spine BMD (ie, $-4.04 \%$ for $\mathrm{LA}$, versus $+0.25 \%$ for dienogest $2 \mathrm{mg}$ at 24 weeks). ${ }^{12}$

\section{Bleeding pattern}

Bleeding pattern data were taken from daily patient diaries. The mean (and median) number of bleeding/spotting days, number of bleeding/spotting episodes, and duration of bleeding/spotting episodes all decreased progressively during continued dienogest $2 \mathrm{mg}$ treatment, ie, through World Health Organization 90-day reference periods 1-5 (up to 15 months). The mean number of spotting-only days and episodes and the duration of spotting-only episodes similarly showed progressive decreases with continued dienogest $2 \mathrm{mg}$ treatment. A consistent pattern of reduced bleeding intensity over time was also associated with prolonged dienogest $2 \mathrm{mg}$ treatment (data not shown).

The bleeding patterns of women in the dienogest $2 \mathrm{mg}$ group more closely resembled placebo-treated than LA-treated women during World Health Organization reference period 1 (months 1-3) (Table 5). The sizes of the standard deviations in Table 5 indicate a large interindividual variability in the number and duration of bleeding episodes in women treated with dienogest $2 \mathrm{mg}$.

\section{Discussion}

In this pooled analysis of 332 women with endometriosis who participated in four clinical trials of dienogest $2 \mathrm{mg}$ in the European development program, dienogest was well tolerated with a favorable safety profile that extended over a period of up to 65 weeks.

AEs in the pooled analyses were generally mild to moderate in intensity and were associated with low discontinuation rates. In addition, the AEs associated with dienogest $2 \mathrm{mg}$ decreased in both incidence and intensity over time. ${ }^{10-12}$ 
Table 5 Bleeding/spotting frequency in pooled dienogest $2 \mathrm{mg}$ group treatment, compared with leuprolide acetate and placebo

\begin{tabular}{|c|c|c|c|c|c|c|}
\hline & \multicolumn{2}{|c|}{ Dienogest 2 mg } & \multicolumn{2}{|c|}{$\begin{array}{l}\text { Leuprolide acetate } \\
3.75 \mathrm{mg} / \mathrm{month}\end{array}$} & \multicolumn{2}{|c|}{ Placebo } \\
\hline & $\mathbf{n}^{\mathbf{a}}$ & Mean \pm SD & $\mathbf{n}$ & Mean \pm SD & $\mathbf{n}$ & Mean \pm SD \\
\hline \multicolumn{7}{|c|}{ Number of bleeding/spotting days } \\
\hline Months I-3 & 281 & $25.1 \pm 16.9$ & 117 & $11.5 \pm 7.0$ & 59 & $22.4 \pm 9.6$ \\
\hline Months 4-6 & 248 & $13.3 \pm 13.7$ & 111 & $1.7 \pm 4.5$ & - & - \\
\hline Months 7-9 & 156 & $12.7 \pm 12.6$ & - & - & - & - \\
\hline Months 10-12 & 146 & $10.2 \pm 10.0$ & - & - & - & - \\
\hline Months 13-15 & 60 & $8.5 \pm 9.0$ & - & - & - & - \\
\hline \multicolumn{7}{|c|}{ Duration of bleeding/spotting episodes (days) } \\
\hline Months I-3 & 253 & $8.25 \pm 8.67$ & 83 & $5.57 \pm 3.77$ & 59 & $5.95 \pm 2.12$ \\
\hline Months 4-6 & 183 & $6.07 \pm 5.66$ & 25 & $4.09 \pm 3.32$ & - & - \\
\hline Months 7-9 & 116 & $5.50 \pm 5.82$ & - & - & - & - \\
\hline Months 10-12 & 104 & $4.70 \pm 2.27$ & - & - & - & - \\
\hline Months 13-15 & 42 & $4.67 \pm 2.49$ & - & - & - & - \\
\hline \multicolumn{7}{|c|}{ Number of spotting-only days } \\
\hline Months I-3 & 281 & $15.0 \pm 13.2$ & 117 & $4.8 \pm 4.2$ & 59 & $9.7 \pm 8.7$ \\
\hline Months 4-6 & 248 & $8.7 \pm 9.8$ & 111 & $0.7 \pm 1.5$ & - & - \\
\hline Months 7-9 & 156 & $8.8 \pm 9.3$ & - & - & - & - \\
\hline Months 10-12 & 146 & $7.3 \pm 7.8$ & - & - & - & - \\
\hline Months I3-15 & 60 & $6.5 \pm 7.5$ & - & - & - & - \\
\hline
\end{tabular}

Notes: aReduction in patient numbers over time is due to varying duration of studies in pooled analysis, and not to patient dropout. Abbreviation: SD, standard deviation.

The pharmacological properties of dienogest, which have been described in detail elsewhere, contribute to the absence of clinically relevant androgenic effects. In comparison to progestins with androgenic activity such as medroxyprogesterone acetate and norethindrone acetate, ${ }^{18-20}$ dienogest has a more favorable profile with low incidences of androgenic effects. ${ }^{10-13,21-23}$ Together, these observations suggest that compliance and adherence to dienogest $2 \mathrm{mg}$ may be favorable in clinical practice.

Laboratory and vital sign assessments in the pooled safety population indicated no safety concerns for dienogest $2 \mathrm{mg}$. Mean estradiol levels in the dienogest $2 \mathrm{mg}$ group showed no consistent change over time but the high standard deviation indicates a substantial degree of variability between individuals. It is notable that mean values in these analyses were higher than those reported in the pharmacodynamic trial of dienogest $2 \mathrm{mg}$ in healthy women, where the mean estradiol concentration was $143.2 \pm 40.4 \mathrm{pmol} / \mathrm{L}(39 \pm 11 \mathrm{pg} / \mathrm{mL}) .{ }^{24}$ Differences in methodologies mean that the data in these studies cannot be directly compared. However, the pharmacodynamic trial in healthy women, which measured serum estradiol levels every third day, may provide a more accurate representation of the effects of dienogest $2 \mathrm{mg}$ when compared with the sporadic assessments of serum estradiol levels performed in the patient trials, and readers are, therefore, referred to the pharmacodynamic paper for a detailed review of these data. ${ }^{24}$ The pharmacodynamic study concluded that estradiol levels are maintained within the "window" proposed in the Barbieri threshold theory, ${ }^{25}$ by which suppression of estrogen levels is sufficient to inhibit the growth of endometriotic lesions, but is moderate enough to prevent hypoestrogenic adverse effects. The pharmacodynamic study also reported, alongside other studies, that normal ovarian function returns promptly following the cessation of dienogest treatment. ${ }^{6,16,24}$

Weight gain is a common adverse effect of progestins including medroxyprogesterone acetate and norethindrone acetate $\mathrm{e}^{6,20,26,27}$ and is often perceived adversely by patients. The current pooled analysis demonstrates that mean weight change during continued dienogest $2 \mathrm{mg}$ treatment is small and is not substantially different from that observed during placebo treatment.

Changes in bleeding pattern are another well-recognized characteristic of many progestins. ${ }^{6}$ The current pooled analysis shows that an initial increase in the number of bleeding/ spotting days and a desynchronized bleeding pattern with dienogest treatment is followed by a progressive reduction in bleeding days during continued treatment, accompanied by increases in amenorrhea rates. Notably, the number of discontinuations due to heavy or irregular bleeding was low (ie, 2 of 332 women), indicating that dienogest $2 \mathrm{mg}$ is well tolerated by women in light of its efficacy for pain relief. Compliance with dienogest treatment is likely to be enhanced in clinical practice if women are informed of the 
potential effects on bleeding at the initiation of treatment. As reported previously, the high rate of amenorrhea reported in LA-treated, compared with dienogest-treated, patients is attributable to the substantial depletion in estrogen levels that is a characteristic of GnRH agonist therapy. ${ }^{12}$

The safety profile of dienogest in endometriosis that is demonstrated in these pooled analyses is supported by other published studies. These include a pilot study of high-dose dienogest (20 mg/day) in Europe ${ }^{28}$ and a Phase II doseranging study, ${ }^{29}$ a Phase III comparator-controlled trial using the $\mathrm{GnRH}$ analog, buserelin acetate, ${ }^{30}$ and two long-term studies $^{16,31}$ in Japan. Even at a high dose of $20 \mathrm{mg} /$ day for 24 weeks, dienogest had no clinically relevant impact on laboratory measures including glucose and lipid metabolism, liver function, electrolyte balance, and hematology ${ }^{28}$ Dienogest also demonstrates a well-characterized, favorable safety and tolerability profile in combination with estradiol for indications including contraception and hormone replacement therapy for menopausal symptoms. ${ }^{32-37}$

No current therapy offers a cure for endometriosis. For many of the medical treatments that are available, there is a paucity of randomized clinical trial evidence on which to base guideline recommendations. As a result, many physicians adopt an empirical approach to therapy, which has the potential for frequent changes in individual treatments based on the patient's response. The current pooled analyses, and the four clinical studies on which they are based, provide clinical evidence that has potential relevance to decision-making. These analyses show that dienogest $2 \mathrm{mg}$ is a well-tolerated therapy with a favorable safety profile that is suitable for long-term use. This favorable profile of dienogest $2 \mathrm{mg}$ is combined with an efficacy equivalent to the highest current treatment standards and offers a progressive improvement in pain during continued use. Reflecting these observations, the guidelines from the World Endometriosis Society have recommended dienogest as an empirical treatment option for women without laparoscopic confirmation and as a suitable adjuvant therapy following endometriosis surgery. ${ }^{38}$

\section{Conclusion}

This analysis of pooled data from the dienogest clinical program in Europe confirms and further characterizes the favorable safety and tolerability profile of dienogest $2 \mathrm{mg}$ for short- and long-term use that was demonstrated in the individual trials. Predictable changes in bleeding pattern, especially at the beginning of dienogest treatment, require adequate counseling to ensure compliance. This pooling of data from well-controlled trials of dienogest represents a contribution to evidence-based medicine in endometriosis, providing outcomes that are of potential relevance to daily practice.

\section{Acknowledgments}

Editorial support was provided by Bill Wolvey at PAREXEL, which was funded by Bayer Pharma.

\section{Disclosure}

TS has no competing interests to report. TF, CG, CA, and CS are full-time employees of Bayer Pharma AG. US is a part-time employee of Jenapharm GmbH \& Co KG.

\section{References}

1. Schrager S, Falleroni J, Edgoose J. Evaluation and treatment of endometriosis. Am Fam Physician. 2013;87(2):107-113.

2. Guo SW. Recurrence of endometriosis and its control. Hum Reprod Update. 2009;15(4):441-461.

3. Vercellini P, Crosignani PG, Abbiati A, Somigliana E, Vigano P, Fedele L. The effect of surgery for symptomatic endometriosis: the other side of the story. Hum Reprod Update. 2009;15(2):177-188.

4. Mounsey AL, Wilgus A, Slawson DC. Diagnosis and management of endometriosis. Am Fam Physician. 2006;74(4):594-600.

5. Luciano AA. Danazol treatment of endometriosis-associated pain. J Minim Invasive Gynecol. 2006;13(6):523-524.

6. Vercellini P, Fedele L, Pietropaolo G, Frontino G, Somigliana E, Crosignani PG. Progestogens for endometriosis: forward to the past. Hum Reprod Update. 2003;9(4):387-396.

7. Oettel M, Breitbarth H, Elger W, et al. The pharmacological profile of dienogest. Eur J Contracept Reprod Health Care. 1999;4(1 suppl 1): 2-13, 1362-5187.

8. Sasagawa S, Shimizu Y, Kami H, et al. Dienogest is a selective progesterone receptor agonist in transactivation analysis with potent oral endometrial activity due to its efficient pharmacokinetic profile. Steroids. 2008;73(2):222-231.

9. Harada T, Taniguchi F. Dienogest: a new therapeutic agent for the treatment of endometriosis. Womens Health (Lond Engl). 2010;6(1):27-35.

10. Kohler G, Faustmann TA, Gerlinger C, Seitz C, Mueck AO. A dose-ranging study to determine the efficacy and safety of 1,2 , and $4 \mathrm{mg}$ of dienogest daily for endometriosis. Int J Gynaecol Obstet. 2010;108(1):21-25.

11. Strowitzki T, Faustmann T, Gerlinger C, Seitz C. Dienogest in the treatment of endometriosis-associated pelvic pain: a 12-week, randomized, double-blind, placebo-controlled study. Eur J Obstet Gynecol Reprod Biol. 2010;151(2):193-198.

12. Strowitzki T, Marr J, Gerlinger C, Faustmann T, Seitz C. Dienogest is as effective as leuprolide acetate in treating the painful symptoms of endometriosis: a 24-week, randomized, multicentre, open-label trial. Hum Reprod. 2010;25(3):633-641.

13. Petraglia F, Hornung D, Seitz C, et al. Reduced pelvic pain in women with endometriosis: efficacy of long-term dienogest treatment. Arch Gynecol Obstet. 2012;285(1):167-173.

14. Kohler G, Goretzlehner G, Brachmann K. Lipid metabolism during treatment of endometriosis with the progestin dienogest. Acta Obstet Gynecol Scand. 1989;68(7):633-635.

15. Kohler G, Goretzlehner G, Amon I. Endometriosetherapie mit Dienogest [Therapy of endometriosis with dienogest]. Zentralbl Gynakol. 1987;109(12):795-801.

16. Momoeda M, Harada T, Terakawa N, et al. Long-term use of dienogest for the treatment of endometriosis. J Obstet Gynaecol Res. 2009;35(6): 1069-1076.

17. Gerlinger C, Endrikat J, Kallischnigg G, Wessel J. Evaluation of menstrual bleeding patterns: a new proposal for a universal guideline based on the analysis of more than 4500 bleeding diaries. Eur J Contracept Reprod Health Care. 2007;12(3):203-211. 
18. Ghatge RP, Jacobsen BM, Schittone SA, Horwitz KB. The progestational and androgenic properties of medroxyprogesterone acetate: gene regulatory overlap with dihydrotestosterone in breast cancer cells. Breast Cancer Res. 2005;7(6):R1036-R1050.

19. Soares SR, Martinez-Varea A, Hidalgo-Mora JJ, Pellicer A. Pharmacologic therapies in endometriosis: a systematic review. Fertil Steril. 2012;98(3):529-555.

20. Vercellini P, Pietropaolo G, De GO, Pasin R, Chiodini A, Crosignani PG. Treatment of symptomatic rectovaginal endometriosis with an estrogenprogestogen combination versus low-dose norethindrone acetate. Fertil Steril. 2005;84(5):1375-1387.

21. Cosson M, Querleu D, Donnez J, et al. Dienogest is as effective as triptorelin in the treatment of endometriosis after laparoscopic surgery: results of a prospective, multicenter, randomized study. Fertil Steril. 2002;77(4):684-692.

22. McCormack PL. Dienogest: a review of its use in the treatment of endometriosis. Drugs. 2010;70(16):2073-2088.

23. Mueck AO. Dienogest: an oral progestogen for the treatment of endometriosis. Expert Rev Obstet Gynecol. 2011;6(1):5-15.

24. Klipping C, Duijkers I, Remmers A, et al. Ovulation-inhibiting effects of dienogest in a randomized, dose-controlled pharmacodynamic trial of healthy women. J Clin Pharmacol. 2012;52(11):1704-1713.

25. Barbieri RL. Hormone treatment of endometriosis: the estrogen threshold hypothesis. Am J Obstet Gynecol. 1992;166(2):740-745.

26. Cundy T, Farquhar CM, Cornish J, Reid IR. Short-term effects of high dose oral medroxyprogesterone acetate on bone density in premenopausal women. J Clin Endocrinol Metab. 1996;81(3):1014-1017.

27. Mahutte NG, Arici A. Medical management of endometriosis-associated pain. Obstet Gynecol Clin North Am. 2003;30(1):133-150.

28. Schindler AE, Henkel A, Moore C, Oettel M. Effect and safety of high-dose dienogest (20 mg/day) in the treatment of women with endometriosis. Arch Gynecol Obstet. 2010;282(5):507-514.
29. Momoeda M, Taketani Y. Randomized double-blind, multicentre, parallel-group dose-response study of dienogest in patients with endometriosis. Jpn Pharmacol Ther. 2007;35(7):769-783.

30. Harada T, Momoeda M, Taketani Y, et al. Dienogest is as effective as intranasal buserelin acetate for the relief of pain symptoms associated with endometriosis - a randomized, double-blind, multicenter, controlled trial. Fertil Steril. 2009;91(3):675-681.

31. Kitawaki J, Kusuki I, Yamanaka K, Suganuma I. Maintenance therapy with dienogest following gonadotropin-releasing hormone agonist treatment for endometriosis-associated pelvic pain. Eur J Obstet Gynecol Reprod Biol. 2011;157(2):212-216.

32. Palacios S, Wildt L, Parke S, Machlitt A, Romer T, Bitzer J. Efficacy and safety of a novel oral contraceptive based on oestradiol (oestradiol valerate/dienogest): a phase III trial. Eur J Obstet Gynecol Reprod Biol. 2010;149(1):57-62.

33. Perez-Campos EF. Ethinylestradiol/dienogest in oral contraception. Drugs. 2010;70(6):681-689.

34. von Schoultz B. Clinical efficacy and safety of combined estradiol valerate and dienogest: a new no-bleed treatment. Climacteric. 2003;6(suppl 2): 24-32.

35. Wellington K, Perry CM. Estradiol valerate/dienogest. Drugs. 2002; 62(3):491-504.

36. Wiegratz I, Stahlberg S, Manthey T, et al. Effects of combined oral contraceptive ethinyl estradiol (30 microg) and dienogest $(2 \mathrm{mg})$ on carbohydrate metabolism during 1 year of conventional or extendedcycle use. Horm Metab Res. 2010;42(5):358-363.

37. Wiegratz I, Stahlberg S, Manthey T, et al. Effects of an oral contraceptive containing $30 \mathrm{mcg}$ ethinyl estradiol and $2 \mathrm{mg}$ dienogest on lipid metabolism during 1 year of conventional or extended-cycle use. Contraception. 2010;81(1):57-61.

38. Johnson NP, Hummelshoj L. Consensus on current management of endometriosis. Hum Reprod. 2013;28(6):1552-1568.
International Journal of Women's Health

\section{Publish your work in this journal}

The International Journal of Women's Health is an international, peerreviewed open-access journal publishing original research, reports, editorials, reviews and commentaries on all aspects of women's healthcare including gynecology, obstetrics, and breast cancer. The manuscript management system is completely online and includes

\section{Dovepress}

a very quick and fair peer-review system, which is all easy to use. Visit http://www.dovepress.com/testimonials.php to read real quotes from published authors. 